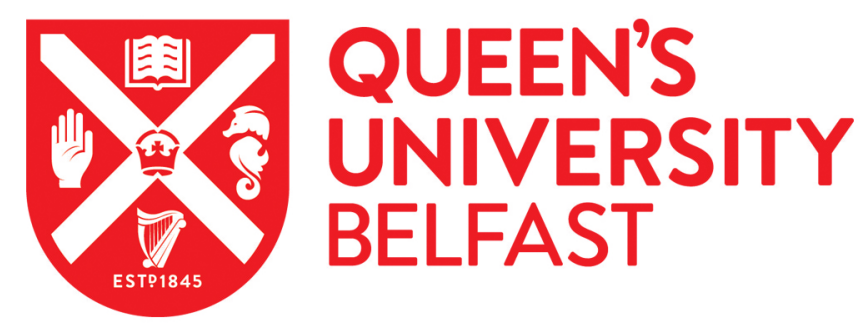

\title{
Novel semi-interpenetrating hydrogel networks with enhanced mechanical properties and thermoresponsive engineered drug delivery, designed as bioactive endotracheal tube biomaterials
}

Jones, D. S., Andrews, G. P., Caldwell, D. L., Lorimer, C., Gorman, S. P., \& McCoy, C. P. (2012). Novel semiinterpenetrating hydrogel networks with enhanced mechanical properties and thermoresponsive engineered drug delivery, designed as bioactive endotracheal tube biomaterials. European Journal of Pharmaceutics and Biopharmaceutics, 82(3), 563-571. https://doi.org/10.1016/j.ejpb.2012.07.019

\section{Published in:}

European Journal of Pharmaceutics and Biopharmaceutics

\section{Document Version:}

Peer reviewed version

Queen's University Belfast - Research Portal:

Link to publication record in Queen's University Belfast Research Portal

\footnotetext{
Publisher rights

This is the author's version of a work that was accepted for publication in European Journal of Pharmaceutics and Biopharmaceutics. Changes resulting from the publishing process, such as peer review, editing, corrections, structural formatting, and other quality contro mechanisms may not be reflected in this document. Changes may have been made to this work since it was submitted for publication. A definitive version was subsequently published in European Journal of Pharmaceutics and Biopharmaceutics, Vol. 82, 11/2012
}

\section{General rights}

Copyright for the publications made accessible via the Queen's University Belfast Research Portal is retained by the author(s) and / or other copyright owners and it is a condition of accessing these publications that users recognise and abide by the legal requirements associated with these rights.

Take down policy

The Research Portal is Queen's institutional repository that provides access to Queen's research output. Every effort has been made to ensure that content in the Research Portal does not infringe any person's rights, or applicable UK laws. If you discover content in the

Research Portal that you believe breaches copyright or violates any law, please contact openaccess@qub.ac.uk. 


\section{Accepted Manuscript}

Research Paper

zurcpean

lournal of

Pharmaceutics and

:iopharmaceutios

Novel semi-interpenetrating hydrogel networks with enhanced mechanical properties and thermoresponsive engineered drug delivery, designed as bioactive endotracheal tube biomaterials

David S. Jones, Gavin P. Andrews, Deborah L. Caldwell, Colin Lorimer, Sean P. Gorman, Colin P. McCoy

PII: S0939-6411(12)00244-5

DOI: http://dx.doi.org/10.1016/j.ejpb.2012.07.019

Reference: EJPB 11194

To appear in: European Journal of Pharmaceutics and Biopharmaceutics

Received Date: 10 December 2011

Accepted Date:

27 July 2012

Please cite this article as: D.S. Jones, G.P. Andrews, D.L. Caldwell, C. Lorimer, S.P. Gorman, C.P. McCoy, Novel semi-interpenetrating hydrogel networks with enhanced mechanical properties and thermoresponsive engineered drug delivery, designed as bioactive endotracheal tube biomaterials, European Journal of Pharmaceutics and Biopharmaceutics (2012), doi: http://dx.doi.org/10.1016/j.ejpb.2012.07.019

This is a PDF file of an unedited manuscript that has been accepted for publication. As a service to our customers we are providing this early version of the manuscript. The manuscript will undergo copyediting, typesetting, and review of the resulting proof before it is published in its final form. Please note that during the production process errors may be discovered which could affect the content, and all legal disclaimers that apply to the journal pertain. 
Novel semi-interpenetrating hydrogel networks with enhanced mechanical properties and thermoresponsive engineered drug delivery, designed as bioactive endotracheal tube biomaterials

David S. Jones*, Gavin P. Andrews, Deborah L. Caldwell, Colin Lorimer, Sean P. Gorman and Colin P. McCoy

School of Pharmacy, Queen's University of Belfast, Medical Biology Centre, 97 Lisburn Road, Belfast BT9 7BL, Northern Ireland

*Address for Correspondence:

School of Pharmacy, Queen's University of Belfast, Medical Biology Centre, 97 Lisburn Road, Belfast BT9 7BL, Northern Ireland

Tel: $\quad 00442890972011$

Fax: $\quad 00442890247794$

e-mail: d.jones@qub.ac.uk

Key Words: Interpenetrating polymer network, Thermoresponsive, Mechanical, Swelling, Drug Release, Confocal laser scanning microscopy 


\section{Abstract}

Thermoresponsive polymeric platforms are used to optimise drug delivery in pharmaceutical systems and bioactive medical devices. However, the practical application of these systems is compromised by their poor mechanical properties. This study describes the design of thermoresponsive semi-interpenetrating polymer networks (s-IPNs) based on cross-linked $\mathrm{p}($ NIPAA) or $\mathrm{p}$ (NIPAA-Co-HEMA) hydrogels containing poly( $\varepsilon$-caprolactone) designed to address this issue. Using DSC, the lower critical solution temperature of the co-polymer and $\mathrm{p}$ (NIPAA) matrices were circa $34^{\circ} \mathrm{C}$ and $32^{\circ} \mathrm{C}$, respectively. $\mathrm{PCL}$ was physically dispersed within the hydrogel matrices as confirmed using confocal scanning laser microscopy and DSC and resulted in marked changes in the mechanical properties (Ultimate tensile strength, Young's modulus) without adversely compromising the elongation properties. P(NIPAA) networks containing dispersed PCL exhibited thermoresponsive swelling properties following immersion in buffer $(\mathrm{pH} 7)$, with the equilibrium-swelling ratio being greater at $20^{\circ} \mathrm{C}$ than $37^{\circ} \mathrm{C}$ and greatest for $\mathrm{p}(\mathrm{NIPAA}) / \mathrm{PCL}$ systems at $20^{\circ} \mathrm{C}$. The incorporation of $\mathrm{PCL}$ significantly lowered the equilibrium swelling ratio of the various networks but this was not deemed practically significant for s-IPNs based on p(NIPAA). Thermoresponsive release of metronidazole was observed from s-IPN composed of $\mathrm{p}(\mathrm{NIPAA}) / \mathrm{PCL}$ at $37^{\circ} \mathrm{C}$ but not from $\mathrm{p}(\mathrm{NIPAA}-\mathrm{CO}-\mathrm{HEMA}) / \mathrm{PCL}$ at this temperature. In all other platforms drug release at $20^{\circ} \mathrm{C}$ was significantly similar to that at $37^{\circ} \mathrm{C}$ and was diffusion controlled. This study has uniquely described a strategy by which thermoresponsive drug release may be performed from polymeric platforms with highly elastic properties. It is proposed that these materials may $\underline{\text { be used clinically as bioactive endotracheal tubes, designed to offer enhanced resistance to }}$ ventilator associated pneumonia, a clinical condition associated with the use of endotracheal tubes where stimulus responsive drug release from biomaterials of significant mechanical properties would be advantageous. 


\section{Introduction}

Hydrogels are conveniently described as water swollen polymeric materials that retain their mechanical and topological structure in the swollen state. The resultant properties of the hydrogels are dependent on several key parameters including the hydrophilicity of the polymer chains and the degree of cross-linking [1]. Hydrogels may be produced from a wide range of materials (both natural and synthetic) and may be synthesised to offer a wide range of properties that are relevant to drug delivery and medical device design [2]. Key to their use as biomaterials is their high water content as this enhances biocompatibility. At equilibrium, hydrogels may contain from 10 to $98 \%$ of water within their polymeric structure [3] although Lydon et al. [4] defined a lower limit of $20 \%$ absorbed weight of water. Both the polymer crosslink density and the degree of hydrophilicity of the polymer govern the extent of polymeric swelling. For this reason (and in addition to their flexibility) hydrogels have been used as contact lenses and urethral catheter coatings for several decades [5-7].

Hydrogels have been successfully employed for the delivery of bioactive agents $[8,9]$. For example, hydrogel-coated catheters have been loaded with antimicrobial agents, their subsequent release being associated with reduced medical device related infection $[1,8]$. Similarly, hydrogels have been used as the platform for the release of anticancer drugs [10]. Drug release from hydrogels is dependent on the physicochemical properties of the drug and the hydrogel and, in addition, the degree of cross-linking [1]. However, in many cases, the release kinetics are inappropriate for the desired application. For example, when used as medical device coatings, it is necessary that the hydrogels contain sufficient water to aid insertion and to maintain comfort in use, however, drug release from such systems is frequently rapid; thereby limiting their resistance to medical device related infection when implanted for longer durations. To optimise their clinical performance, hydrogels have been 
designed in which drug release is mediated by external stimuli [11], e.g. $\mathrm{pH}[12,13]$, applied magnetic or electrical fields [14, 15], ultrasound [16], enzymatic action and/or light [17]. Hydrogels, primarily based on poly( $\mathrm{N}$-isopropyl acrylamide), have been designed to respond to temperature as an external stimulus. In such systems a change in the phase of the polymer occurs at a defined temperature, referred to as the Lower Critical Solution Temperature (LCST) $[18,19]$. Below the LCST, the hydrophilic nature of this polymer facilitates water uptake whereas above the LCST, hydrophobic interactions between the polymer chains result in a collapse of the three-dimensional hydrogel structure and the resultant "responsive" release of drug. Several biological applications for this polymer have been cited including, cell grafting [18], gene delivery [20] and drug delivery [21, 22].

The compromised mechanical properties of hydrogels often limit the scope of their applications within medicine [23]. For example, the poor mechanical properties (low ultimate tensile strength, low Young's modulus) limit their use to coatings of medical devices, however, despite this, problems in use, e.g. delamination, fracture upon the application of normal stresses, may occur. The mechanical properties of hydrogels may be improved by copolymerisation [19], improving crosslink density [1, 24] and using composites, however, whilst incremental improvements have been reported, these strategies are associated with associated disadvantages including modification of the equilibrium water content and adverse modification of drug release profiles. P(NIPAA) hydrogels have been previously reported to possess poor mechanical properties, which have in turn limited their thermoresponsive properties and their potential clinical applications $[19,25]$. For example, copolymerisation of NIPAA with acrylate monomers has been reported to enhance the mechanical properties but adversely affect the thermoresponsive properties [19]. Enhancing the crosslink density of $p$ (NIPAA) hydrogels decreases the 
temperature dependent volume change of the polymer, which in turn affect water uptake and the degree of thermoresponsive behaviour. Therefore, strategies are needed to address this deficiency to ensure that hydrogels are developed that offer optimal drug release, equilibrium water content and mechanical properties.

Within this landscape, this study presents a novel strategy to address this deficiency in which the mechanical properties of thermoresponsive hydrogels may be engineered by the formation of a semi-interpenetrating polymer network (s-IPN) with poly( $\varepsilon$-caprolactone) without the attendant loss of thermoresponsive drug release. It is suggested that the approach presented in this study would be of considerable benefit for drug delivery systems/bioactive devices in which stimulus-responsive release is required from mechanically robust platforms, e.g. medical implants. In particular, it is proposed that these $\underline{\text { systems may be employed as bioactive biomaterials for use as endotracheal tubes, designed }}$ to reduce mortality associated with ventilator associated pneumonia [26]. In particular drug loading of these systems may be performed by nebulisation of solutions of antimicrobial agents at temperatures below the lower critical solution temperature whereas, release, facilitated by mechanical changes to the network, will occur at temperatures above the lower critical solution temperature. The thermal stimulus may be achieved by controlling the temperature of inspired air. This is the first report of a strategy in which thermoresponsive polymer platforms based on $\mathrm{p}$ (NIPAA) offering suitable mechanical properties have been designed as endotracheal tube biomaterials. 


\section{Materials and Methods}

\section{$2.1 \quad$ Materials}

All chemicals were used as received, requiring no further purification. 2',2'-Azobis-2methylpropionitrile 98\% (AIBN) was purchased from Janssen Chimica, Beerse, Belgium and Labscan, Dublin, Ireland, respectively. Poly( $\varepsilon$-caprolactone) high molecular weight 50,000 was a gift from Solvay Caprolactones, Warrington, England whereas Metronidazole, Acridine Orange, Rhodamine B base, N-isopropylacrylamide (NIPAA), Ethylene glycol dimethacrylate (EGDMA) and 2-Hydroxyethyl methacrylate (HEMA) were purchased from Sigma Aldrich Co., Dorset, England. All other chemicals were purchased from BDH Laboratories, Poole, Dorset, England and were of AnalaR or equivalent grade.

\subsection{Materials Synthesis}

Poly(HEMA) was prepared by free radical polymerisation, as previously described by the authors $[1,27,28]$. Briefly, the required masses of monomer, initiator (AIBN $1 \% \mathrm{w} / \mathrm{w}$ ), metronidazole ( $1 \% \mathrm{w} / \mathrm{w}$, as a model drug) and crosslinker (EGDMA, 1\% w/w) were mixed by stirring, then injected between two glass plates separated by silicone tubing spacer and release liner and heated at $90^{\circ} \mathrm{C}$ for one hour. Preparation of poly(NIPAA) and copolymers of NIPAA and HEMA was similarly performed by free radical polymerisation by mixing the required masses of NIPAA (and when required HEMA), EGDMA (1\% w/w), AIBN (1\% w/w) and metronidazole $(1 \% \mathrm{w} / \mathrm{w})$ prior to polymerisation as described above. Finally, the preparation of the semi-IPNs was performed according to a modification of the method described by Jones et al. [29]. In this poly( $\varepsilon$-caprolactone) (5.0g) was melted in the HEMA monomer $(46.0 \mathrm{~g})$ with stirring at circa $50^{\circ} \mathrm{C}$. After cooling to approximately $30^{\circ} \mathrm{C}$, ethylene glycol dimethacrylate (EGDMA, 1g), AIBN (1g), metronidazole (1g) and NIPAA (46.0g) were 
mixed and the solution injected into glass moulds separated by silicone tubing spacer and release liner. The system was maintained at $60^{\circ} \mathrm{C}$ for 1 hour to ensure homogeneous dispersion of the components and then polymerised at $90^{\circ} \mathrm{C}$ for one hour.

\subsection{Mechanical analysis}

Tensile analysis of hydrated polymer samples was performed using a Stable Micro Systems TA-XT2 Texture Analyser (Goldaming, Surrey, UK) interfaced with a personal computer. $\underline{\text { Initially the polymer samples were hydrated to equilibrium in phosphate buffered saline at }}$ $\underline{\mathrm{pH} 7}$ and $20 \pm 1^{\circ} \mathrm{C}$. Rectangular samples were cut from the swollen s-IPNs to dimensions of $5 \mathrm{~cm}$ by $1 \mathrm{~cm}$ using a razor blade and accurately measured using digital Vernier callipers. Each sample strip was examined to ensure there were no jagged edges, before excess surface moisture was removed by gentle blotting with filter paper. To protect the ends of the test sample from the metal grips, adhesive pads (Sellotape ${ }^{\circledR}$ "Sticky Fixers") were applied to both sides of the ends, thus making the effective length of the sample $3 \mathrm{~cm}$. Samples were loaded into position between the mobile upper and static lower clamps and checked for proper alignment before initiation of the test. The upper clamp was raised at a fixed speed of $1.0 \mathrm{~mm} \mathrm{~s}^{-1}$ until fracture of the film occurred. All analyses were performed at $20 \pm$ $\underline{1^{\circ} \mathrm{C} .}$ From the resultant force versus distance plot, the ultimate tensile strength, Young's modulus and percentage elongation were calculated [29].

\subsection{Determination of the swelling ratio}

Five $1 \mathrm{~cm}^{2}$ replicates of the polymer samples under examination were initially dried, weighed accurately and transferred to McCartney bottles containing $25 \mathrm{ml}$ of buffer solution $(\mathrm{pH} 7$ phosphate buffered saline) at either $20^{\circ} \mathrm{C}$ or $37^{\circ} \mathrm{C}$. At specified times each sample was 
removed, blotted dry between 2 pieces of filter paper (to remove excess surface buffer) and weighed. The polymer samples were then returned to the buffer solution until the next time period.

The swelling ratio (SR) was calculated using the equation below:

$S R=\frac{W_{w e t} W_{d r y}}{W_{d r y}}$

Where:

$W_{\text {wet }}$ and $W_{\text {dry }}$ refer to the weights of the sample when wet and dry (initial weight).

2.5 Examination of the Thermal Properties of Selected Materials using Differential Scanning Calorimetry

The thermal properties of selected s-IPNs and their parent hydrogels were examined using differential scanning calorimetry. In this, samples were placed in pans and hermetically sealed with a pinhole lid. Thermal analysis was performed using a TA Instruments MTDSC 2920 (Leatherhead, Surrey), following calibration with Indium. A heating rate of $2^{\circ} \mathrm{C} \mathrm{min}^{-1}$ was applied over a temperature range of 20 to $180^{\circ} \mathrm{C}$. In all cases at least quadruplicate measurements of the relationship between heat flow and temperature were determined.

\subsection{Confocal laser-scanning microscopy (CLSM)}

The physical natures of the s-IPNs were investigated using confocal laser-scanning microscopy (CLSM). A $1 \% \mathrm{w} / \mathrm{v}$ acridine orange (hydrophilic stain) aqueous solution was prepared by dissolving the stain $(1.0 \mathrm{~g})$ in water $(100 \mathrm{ml})$. Similarly, a $0.05 \% \mathrm{w} / \mathrm{v}$ solution of 
rhodamine B base (hydrophobic stain) was prepared by dissolving $0.05 \mathrm{~g}$ of the stain in water $(100 \mathrm{ml})$. The polymers were firstly stained with a drop of the individual dyes and examined using a Leica TCS SP2 confocal laser-scanning microscope, using a 10x objective. For acridine orange, excitation of the sample was from the $488 \mathrm{~nm}$ line of an Ar/ArKr laser, with detection between $498-574 \mathrm{~nm}$. This acridine orange emission is shown in green in the micrographs (Figure 2 a and 2c). For rhodamine B base, excitation of the sample was from the $543 \mathrm{~nm}$ line of a GreNe laser, with detection between $565-650 \mathrm{~nm}$. The rhodamine B base emission is shown in red in the micrographs (Figure $2 b$ ).

The second part of the study involved preparing a mixed acridine orange/rhodamine B base stain by mixing equal volumes of these two solutions. Acridine orange exclusively stained the hydrophilic hydrogel regions in the network whilst the hydrophobic rhodamine B base stained the PCL regions preferentially. Using line-by-line sequential scanning, images were obtained which allow the macro domains of both amorphous and crystalline PCL to be visualised simultaneously along with the interpenetrating channels of the hydrogel.

\subsection{Metronidazole release}

Samples of the drug loaded s-IPNs and parent hydrogels $(10 \times 10 \mathrm{~mm})$ were placed into a $M^{c}$ Cartney bottle containing $30 \mathrm{ml}$ buffer solution of the required $\mathrm{pH}$ and placed into a shaking water bath at either $20^{\circ} \mathrm{C}$ or $37^{\circ} \mathrm{C}$ and 60 shakes $\min ^{-1}$. Sink conditions were maintained under these conditions. At specified time points, the polymer samples were transferred to another $M^{c}$ Cartney bottle containing $10 \mathrm{ml}$ buffer solution while the original sample medium was analysed at $320 \mathrm{~nm}$ using UV spectrophotometry. The mass of metronidazole in the samples of dissolution media was calculated by reference to a freshly prepared calibration curve prepared in the buffer system $(r>0.99)$. 


\subsection{Statistical Analysis}

For tensile analysis, the effect of hydrogel composition and PCL concentration on the ultimate tensile strength, Young's modulus, percentage elongation and thermal properties were statistically evaluated using a two-way Analysis of Variance (ANOVA). A two-way ANOVA was used to statistically analyse the effects of film composition and temperature on the swelling ratio. Similarly, for the drug release experiments, a two-way repeated measures ANOVA was used to statistically analyse the effects of film composition and temperature on drug release. Post-hoc comparisons of the means of individual results were performed using the Neuman-Keuls test and in all cases $\mathrm{p}<0.05$ denoted significance [30]. 


\section{Results}

The mechanical properties of the various platforms under investigation are presented in table one. As may be observed the mechanical properties (ultimate tensile strength, percentage elongation and Young's modulus) were affected by both the composition of the hydrogel component of the network and the concentration of PCL. The mechanical properties of the networks were dependent on the composition of the parent hydrogel platform. Increasing the ratio of HEMA to NIPAA significantly increased the ultimate tensile strength and Young's modulus but decreased the percentage elongation at break. Increasing the $\mathrm{PCL}$ content within the network sequentially increased the ultimate tensile strength and Young's modulus but decreased the \% elongation at break of these materials. Importantly, whilst the incorporation of PCL significantly decreased the $\%$ elongation at break of the various hydrogels, these systems still retained useful elongation properties. Furthermore, whilst the mechanical properties of the poly(NIPAA) hydrogel were limited, the incorporation of $\mathrm{PCL}$ rendered these systems more suitable for clinical use. Determination of the mechanical properties of the materials under investigation at temperatures above the lower critical solution temperature $\left(37^{\circ} \mathrm{C}\right)$ was not quantitatively performed due to the irregular dimensions of the samples. However qualitatively the sIPNs $\underline{\text { exhibited ultimate tensile strength values that were both considerable and consistent with }}$ those of the materials when measured below the lower critical solution temperature.

Table two illustrates the effect of network composition and temperature of the bathing medium ( $\mathrm{pH} 7$, phosphate buffered saline) on the equilibrium-swelling ratio of the various networks under investigation. As may be observed both the composition of the network and temperature significantly affected the equilibrium-swelling ratio. Thermoresponsive behaviour was noted for all NIPAA containing hydrogels, both in the absence and presence of PCL, whereas, as expected, poly(HEMA) hydrogels either containing or devoid of PCL did 
not show thermoresponsive swelling behaviour. These results explained the significant interaction component that was observed in the ANOVA. The temperature dependency of the poly(NIPAA) hydrogels was most pronounced. The swelling properties of the hydrogel co-polymer systems containing 1-20\% w/w PCL were similar. Accordingly in such systems, increasing the mass of PCL did not affect the equilibrium swelling properties and, importantly, enabled these systems to offer thermoresponsive behaviour. In poly(NIPAA) based hydrogel systems the incorporation of PCL significantly lowered the equilibrium swelling ratio at $20^{\circ} \mathrm{C}$ in a concentration-dependent manner, however, it is important to note that even in the presence of $20 \% \mathrm{w} / \mathrm{w} \mathrm{PCL}$, these systems retained their thermoresponsive properties and showed a circa 5 fold swelling at $20^{\circ} \mathrm{C}$.

The release of a model drug, metronidazole, expressed as the times for $10 \%, 30 \%$ and $50 \%$ of the original mass of metronidazole to be released, from the various network systems, at either $20^{\circ} \mathrm{C}$ or $37^{\circ} \mathrm{C}$ under sink conditions (into $\mathrm{pH} 7.4$ buffer) is shown in table three. Furthermore, the release profiles of metronidazole from exemplar networks are shown in Figure one. In addition, the release of metronidazole from the aforementioned systems was modelled according to the generalised power law model [31] (table four). In the absence of PCL the release exponents of poly (HEMA) hydrogels were $0.64 \pm 0.02$ and $0.66 \pm 0.04$ at $20^{\circ} \mathrm{C}$ and $37^{\circ} \mathrm{C}$, respectively. Similarly the release exponent of poly(NIPAA) at $20^{\circ} \mathrm{C}$ was $0.65 \pm$ 0.30 however the rapid release resulting from the thermoresponsive nature of this material did not enable measurement of the release exponent. In the presence of PCL (at either 10 or $20 \% \mathrm{w} / \mathrm{w}$ ), the release exponents of the co-polymer s-IPNs were statistically similar to 0.5 from which it may be inferred that diffusion controlled released occurred. Furthermore, the release exponent of metronidazole was unaffected by increasing $P C L$ concentration. $P C L$ containing poly(NIPAA) s-IPNs exhibited diffusion controlled release at $20^{\circ} \mathrm{C}$ but at $37^{\circ} \mathrm{C}$, the 
thermoresponsive release of metronidazole from these systems rendered this measurement impossible.

Regarding the release kinetics, increasing the concentration of PCL significantly increased the times required for 10,30 and $50 \%$ release of metronidazole at both $20^{\circ} \mathrm{C}$ and $37^{\circ} \mathrm{C}$ for systems based on poly(HEMA) and poly(HEMA-co-NIPAA). In these systems, the times required for the release of a known percentage of metronidazole were similar at $20^{\circ} \mathrm{C}$ and $37^{\circ} \mathrm{C}$. Importantly, the network systems composed of poly(NIPAA) and PCL (either 10 or $20 \%$ $\mathrm{w} / \mathrm{w})$ displayed thermoresponsive drug release, the release at $20^{\circ} \mathrm{C}$ being sustained and diffusion controlled whereas, in comparison, drug release at the higher temperature was comparatively rapid.

Confocal laser scanning micrographs of s-IPN composed of poly(NIPAA) and PCL (10\% w/w) that had been stained with acridine orange, rhodamine B or concurrently with both dyes are presented in Figure 2a, b and c, respectively. In these micrographs the hydrophilic and hydrophobic regions are stained green and red, respectively. The two dyes fluoresced independently of each other. In figure $2 c$ the hydrophilic and hydrophobic domains were stained simultaneously, illustrating the biphasic distribution of the s-IPN.

The effect of network composition on the thermal behaviour of selected networks is shown in table 5. In the absence of PCL, poly(NIPAA) and poly(NIPAA-co-HEMA, 1:1 ratio) exhibited endotherms at $31.51 \pm 1.52^{\circ} \mathrm{C}$ and $142.04 \pm 2.02^{\circ} \mathrm{C}$ for $p\left(\right.$ NIPAA) and at $34.87 \pm 1.02^{\circ} \mathrm{C}$ and $130.05 \pm 1.83{ }^{\circ} \mathrm{C}$ for $\mathrm{p}$ (NIPAA-CO-HEMA). The lower endotherm is indicative of the lower critical solution temperature whereas the higher endotherm reflects a glass transition 
temperature. Hydrogel composition significantly affected the glass transition and lower critical solution temperatures. Incorporation of PCL $(20 \% \mathrm{w} / \mathrm{w})$ did not significantly affect the temperature at which either transition occurred however, in these systems a third endotherm was noted at circa $59^{\circ} \mathrm{C}$, the position of which was unaffected by the chemical composition of the hydrogel network and may be attributed to the melt endotherm of dispersed PCL. 


\section{Discussion}

As a result of their limited mechanical properties, the clinical use of hydrogels has been restricted to certain (defined) applications e.g. contact lenses, soft tissue implants, constructs for tissue engineering and coatings for medical devices $[8,23]$. In addition to their use as medical implants/devices, hydrogels have found extensive use as drug delivery systems in which drug release may be diffusion controlled or facilitated by an external stimulus, e.g. pH, temperature [32-34]. Whilst other polymeric candidates have been examined as platforms for thermoresponsive drug delivery, e.g. poloxamers $[35,36]$, the majority of thermoresponsive drug delivery platforms have involved poly(NIPAA) or copolymers of this monomer with other acrylate monomers [37-41]. Although the ability to poly(NIPAA)-based polymers to offer stimuli sensitive release has been recognised, one of the main limitations associated with the use of these systems as bioactive implants is their sub-optimal mechanical properties [23, 42]. To enhance their mechanical properties (and hence augment their clinical applications), copolymerisation with other monomers, e.g. acrylic acid, methacrylic acid and methacrylic acid esters or the addition of cross-linkers have been reported $[19,43,44]$. However, there are limitations with these approaches including, reductions in the equilibrium water content and deleterious effects on the thermoresponsive behaviour. Therefore, there is a pharmaceutical need to develop platforms that offer both thermoresponsive behaviour and whose mechanical properties are robust and may be engineered to meet specific clinical demands. Uniquely, this study reports a platform technology that addresses these issues, thereby enhancing the scope of applications for which p(NIPAA) based polymers may be used. This is the first report of the use of thermoresponsive materials designed for use as bioactive endotracheal tubes for the prevention of ventilator associated pneumonia. 
The platforms described in this study were prepared by dispersion of molten PCL within the liquid monomer/crosslinker mixture, followed by free radical polymerisation. In a previous study, the authors confirmed that when polymerised in this manner, HEMA and NIPAA form a copolymer [19]. The composition of the hydrogel networks in this study was shown to affect the physicochemical performance of the networks. Examination of the thermal properties of the PCL-containing s-IPNs under examination revealed a melt endotherm (at circa $59^{\circ} \mathrm{C}$ ), which was statistically similar to the melt temperature of PCL $[45,46]$, confirming the existence of $\mathrm{PCL}$ as a disperse phase within the hydrogel matrix. In addition, two thermal (glass) transitions were observed that may be accredited to p(NIPAA) (142.04 \pm $\left.2.02^{\circ} \mathrm{C}\right)$ and $\mathrm{p}(\mathrm{HEMA}-\mathrm{CO}-\mathrm{NIPAA})\left(130.05 \pm 1.83^{\circ} \mathrm{C}\right)[19]$, the magnitudes of which were unaffected by the presence of PCL. The presence of PCL as a disperse phase within the hydrogel platforms was further confirmed using confocal laser scanning microscopy, in conjunction with the use of dyes that selectively stained the hydrophilic (acridine orange) and hydrophobic areas (rhodamine B) of the platforms. As may be observed from figure two the dyes allowed visualisation of these discrete domains, providing further evidence of the disperse nature of PCL within the hydrogel. Interestingly this is one of the few reports that have involved the use of confocal laser scanning microscopy (with two stain specific dyes) to visualise the physical structure of polymer blends.

Typically, the mechanical properties of poly(HEMA) networks exceeded those of the (HEMA: NIPAA) copolymer and poly(NIPAA), the properties of poly(NIPAA) being unsuitable for clinical application as an implant or as a medical device biomaterial, where the ability to insert and removal the material is important. Despite the incorporation of a crosslinker (EGDMA), the inappropriate mechanical properties of poly(NIPAA) systems suggested that the number and/or strength of interchain interactions between adjacent poly(NIPAA) chains 
were lower than those between adjacent chains of poly(NIPAA-co-HEMA) and poly(NIPAA). The lower Young's modulus and higher \% elongation at break illustrates the greater ability of poly(NIPAA) and the copolymer to undergo plastic deformation, highlighting the lower elasticity of these systems. Accordingly in situations where the maintenance of the shape of the drug delivery system is important, e.g. as an implant/insert, hydrogels based on p(NIPAA) would be unsuitable. Incorporation of PCL (in a concentration-dependent fashion) within the hydrogel matrix significantly enhanced the elastic properties of the various networks, these observations being accredited to the presence of $\mathrm{PCL}$ as a disperse, solid phase acting as a filler [47]. Of particular interest are the dramatic enhancements of the ultimate tensile strength and Young's modulus of $p$ (NIPAA) hydrogels in the presence of 10 or $20 \% \mathrm{w} / \mathrm{w} \mathrm{PCL}$, properties that would be suitable for use for applications in which the mechanical properties are essential to the use of the product. In addition, the increase in the ultimate tensile strength and Young's modulus of these materials was not associated with a compromised percentage elongation at break. It is proposed that that materials described in this study would offer particular promise as endotracheal tube biomaterials in which drug loading may be performed by nebulisation of an antimicrobial solution at temperatures below the lower critical solution temperature and drug release may be subsequently initiated by the inspiration of warm air at temperatures exceeding the lower critical solution temperature. To evaluate the mechanical properties of the materials it is appropriate to compare the said properties to those of endotracheal polyvinyl chloride (PVC). In a previous publication [48], the physicochemical properties of endotracheal tube PVC both containing and devoid of drug were characterised. Typically the ultimate tensile strength, \% elongation at break and Young's modulus of PVC were $2.89 \pm 0.00 \mathrm{MPa}$, $\underline{285.93 \pm 10.28 \text { and } 1.12 \pm 0.05 \mathrm{MPa} \text {, respectively, which, following incorporation of drug }(1 \% \text {, }}$ akin to this study) were modified to $1.28 \pm 0.00 \mathrm{MPa}, 114.71 \pm 5.28$ and $1.15 \pm 0.08 \mathrm{MPa}$, respectively. The mechanical properties of the sIPNs described in this study were 
comparable to endotracheal tube PVC and indeed, in some instances the resistance of the sIPNs to fracture was greater than that of PVC. With the exception of certain drug containing sIPNs (50:50 HEMA:NIPAA containing 1, 5 and 10\% PCL), the elongation at break of the sIPNs was generally lower than that of PVC, however, as patients who use these medical devices are immobile, the reduction in magnitude of this parameter would not cause a concern clinically. The elasticity of the s-IPN would be sufficient to resist deformation in use and to facilitate insertion into the trachea without damaging the respiratory tract. Furthermore, the ultimate tensile strength of these s-IPNs are sufficient to prevent fracture during insertion and in situ. Accordingly, it is suggested that the $\underline{\text { mechanical properties of the s-IPNs described in this study would be sufficient to allow their }}$ application as endotracheal tube biomaterials in their own right.

In this study the equilibrium swelling ratios of the networks were examined as functions of temperature and composition and illustrated the effects of hydrogel composition and $\mathrm{PCL}$ loading on this parameter. Increasing the PCL content significantly lowered the equilibriumswelling ratio at $25^{\circ} \mathrm{C}$ and (in general) at $37^{\circ} \mathrm{C}$. These observations may be accredited to the reduction in the (hydrophilic) hydrogel component within the network and the subsequent reduction in free hydrogel volume. A disparity in the equilibrium swelling ratios at $25^{\circ} \mathrm{C}$ and $37^{\circ} \mathrm{C}$ was observed in polymer networks composed of NIPAA or NIPAA: HEMA copolymers in which the equilibrium-swelling ratio of $25^{\circ} \mathrm{C}$ was significantly greater than that at $37^{\circ} \mathrm{C}$. Furthermore, the equilibrium swelling properties of poly(NIPAA) systems were markedly greater than those of comparator systems composed of poly(HEMA-co-NIPAA) at $25^{\circ} \mathrm{C}$ although the differences were not apparent at the higher temperature. Following thermal characterisation, the lower critical solution temperatures of the $p$ (NIPAA-Co-HEMA) and $p\left(\right.$ NIPAA) matrices (both in the presence and absence of $\mathrm{PCL}$ ) were circa $34^{\circ} \mathrm{C}$ and $32^{\circ} \mathrm{C}$, 
respectively. Accordingly, the equilibrium-swelling ratios reflect the swelling below and above the lower critical solution temperature. The temperature independent equilibrium swelling ratios of poly(HEMA) and $\mathrm{PCL}$ containing poly(HEMA) confirm the non-thermally responsive properties of these systems. The presence of $\mathrm{PCL}$ decreased the equilibriumswelling ratio of systems composed of poly(NIPAA) and poly(NIPAA-Co-HEMA), however the most dramatic effect on this parameter was associated with the poly(NIPAA)/PCL (20\%w/w) S-IPN. The significance of these observations is two-fold. Firstly, where drug loading is facilitated by immersion of the xerogel into a saturated drug solution, materials that exhibit the greatest equilibrium-swelling ratio will also exhibit the greatest drug loading. Secondly, the polymeric systems that exhibit the greatest reduction in equilibrium swelling ratio would be expected to offer thermoresponsive drug release. Again of great interest to the aim of this study is the pronounced thermoresponsive properties of poly(NIPAA) platforms containing PCL $(10$ or $20 \% \mathrm{w} / \mathrm{w})$. The incorporation of $\mathrm{PCL}$ significantly lowered the thermoresponsive response however the magnitude of this reduction was small. Typically there was a ten-fold reduction in the volume of these systems below and above the LCST), even in the presence of PCL. Accordingly, in addition to the improved mechanical properties of these systems resultant from the inclusion of $\mathrm{PCL}$, maintenance of pronounced thermoresponsive properties was observed.

Examination of the drug release properties of the various polymer platforms under investigation revealed interesting observations regarding the effects of temperature induced volume changes on this parameter. As expected, PCL containing poly(HEMA) s-IPNs did not exhibit thermoresponsive drug release. However, whilst not thermoresponsive, the release of drug from these systems was controlled and prolonged, with typically circa $70 \%$ of the drug payload being released over a 10 hour period. Typically the release of water soluble 
drugs (e.g. metronidazole) from p(HEMA) is rapid and uncontrolled [1]. Accordingly, these systems, whilst not applicable for this chosen application, may offer opportunities for other medical devices, e.g. intravaginal drug-containing implants. PCL containing poly(NIPAA) sIPNs exhibited pronounced thermoresponsive release of metronidazole. Interestingly, PCL containing poly(HEMA-co-NIPAA) platforms, despite illustrating temperature-dependent changes in volume, did not exhibit thermoresponsive release of metronidazole, illustrated by statistically similar $t_{10 \%}, t_{30 \%}$ and $t_{50 \%}$ values. Following application of the generalised release model [49], the release exponents for all PCL containing poly(HEMA-Co-NIPAA) platforms were circa 0.5 , at each temperature, inferring diffusion (not thermoresponsive) drug release occurred in these systems. It may be therefore inferred that the reduction in volume of these platforms was insufficient to release the drug in a pulsatile fashion or alternatively, the temperature induced rheological (sol-gel) changes occurred prior to the commencement of drug transport. As a result, despite the mechanical improvements offered by the incorporation of PCL within the hydrogel copolymers, these systems do not offer thermoresponsive functionality thereby negating their use as thermoresponsive drug delivery implants. It is important to note the thermoresponsive behaviour of the $\mathrm{PCL}$ containing poly(NIPAA) platforms. In this the entire drug payload was released within $1 \mathrm{~h}$, despite the enhancement of the structure due to the presence of the dispersed hydrophobic phase.

As defined previously the systems described in this manuscript are designed for use as $\underline{\text { bioactive endotracheal tubes, their mechanical properties being sufficient to enable their }}$ use as the sole constituent of the endotracheal tube (i.e. no coating technologies are required). Ventilator associated pneumonia is frequently associated with the use of endotracheal tubes and then has been itself shown to be due to biofilm on the luminal surface of the endotracheal tube [26]. Strategies for the prevention/treatment of ventilatorassociated pneumonia are therefore targeted at the removal of the microbial biofilm. Whilst 
in the biofilm, the resistance of microorganisms to antimicrobial agents is markedly increased (up to 1000 fold increase) [50]. Associated with this problem is the inability to achieve sufficiently high concentrations of antimicrobial agent at the luminal surface of the device. Therefore alternative strategies have been developed to address these issues including the use of bioactive endotracheal tubes $[51,52]$ and the direct nebulization of antimicrobial surfaces across the luminal surfaces of the device and into the lungs [53]. Typically there is a limited volume of fluid at the luminal surface, therefore presenting a thermodynamic resistance to drug diffusion from the bioactive device. The strategy described in this manuscript has successfully addressed this concern; the associated volume change due to changes in the environmental temperature effectively mechanically driving the drug solution from the polymeric network. Akin to traditional strategies for the treatment of infection, a pulsed released of drug offers is preferred to achieve the highest concentration at the site of action and hence achieve the greatest kill kinetics. Therefore, the observed pulsed release in which the drug load was effectively released over a short period is optimal for the prevention/treatment of ventilator-associated pneumonia. Key to the function of these systems within the clinical environment is the control of temperature within the environment of the endotracheal tube. This may be readily controlled in a number of ways. Firstly, loading of the drug may be achieved by nebulization of an antimicrobial solution at a temperature below the lower critical solution temperature of the polymer platform; the swelling of the polymer will enable an effective uptake of the solution within the network. Maintenance of this temperature within the respiratory tract may be performed by controlling the temperature of the inspired air. Under which conditions drug $\underline{\text { release will not occur due to the thermodynamic restraints imposed by the system due to }}$ the limited volume of fluid adjacent to the luminal surface of the device. When required the temperature of the inspired air may be elevated temporarily to ensure that the temperature of the air surrounding the device exceeds the lower critical solution temperature of the 
polymer network. Under these conditions, drug release will be facilitated by a change in the volume of the polymer network, a process that is not dependent on diffusion. This ability to offer pulsatile drug release that is modulated by the temperature of the inspired air is suggested to be particular applicable for the improved treatment/prevention of ventilator associated pneumonia. 


\section{Conclusions}

This study describes the design of thermoresponsive semi-interpenetrating polymer networks based on crosslinked poly(NIPAA) or poly(NIPAA-co-HEMA) hydrogels containing poly( $\varepsilon$-caprolactone) that are designed for use as endotracheal tube biomaterials. The lower critical solution temperature of the co-polymer and poly(NIPAA) matrices were circa $34^{\circ} \mathrm{C}$ and $32^{\circ} \mathrm{C}$, respectively, confirming the thermoresponsive behaviour of these systems at physiological temperatures. PCL was physically dispersed within the hydrogel matrices as confirmed using confocal laser scanning microscopy and differential scanning calorimetry. The elastic properties of poly(NIPAA) hydrogels were lower than comparator hydrogels composed of poly(NIPAA-co-HEMA) or poly(HEMA). Incorporation of PCL significantly and markedly increased these elastic properties and rendered poly(NIPAA) systems suitable for use as implantable materials. Poly(NIPAA) containing s-IPNs exhibited thermoresponsive swelling following immersion in an aqueous phase, with the equilibrium-swelling ratio being greater at $20^{\circ} \mathrm{C}$ than $37^{\circ} \mathrm{C}$ and greatest for poly(NIPAA)/PCL S-IPNs at $20^{\circ} \mathrm{C}$. The incorporation of PCL significantly lowered the equilibrium swelling ratio of poly(NIPAA) at

$20^{\circ} \mathrm{C}$. Thermoresponsive release of metronidazole was observed from s-IPNs composed of poly(NIPAA)/PCL at $37^{\circ} \mathrm{C}$ but not from s-IPNs composed of poly(NIPAA-Co-HEMA)/PCL at this temperature. In all other platforms drug release at $20^{\circ} \mathrm{C}$ was significantly similar to that at $37^{\circ} \mathrm{C}$ and was diffusion controlled. In conclusion, the biomaterials described in this study exhibited combined properties of enhanced mechanical properties (ultimate tensile strength, \% elongation at break and the Young's Modulus) and the thermoresponsive release of a model hydrophilic antimicrobial drug. The mechanical properties of these materials would ensure the necessary ease of insertion without undue damage to the respiratory mucosa and rigidity in use, the latter facilitation patency of airflow, the key physiological demand of endotracheal tubes. Due to the thermoresponsive properties of the biomaterials, drug loading may be performed by nebulising an antimicrobial solution at a 
temperature below the lower critical solution temperature of the polymer network. Drug release may then be activated by increasing the temperature of the inspired air above the lower critical solution temperature, the rapid release of a high concentration of drug offering the optimum opportunity to resolve the microbial biofilm on the luminal surface of the endotracheal tube. It is suggested that the biomaterials described in this study offer a novel strategy for the prevention/treatment of ventilator-associated pneumonia. 


\section{References}

[1] D.S. Jones, G.P. Andrews, S.P. Gorman, Characterisation of cross-linking effects on the physicochemical and drug diffusional properties of cationic hydrogels designed as bioactive urological biomaterials, J. Pharm. Pharmacol., 57 (2005) 1251-1259.

[2] N.A. Peppas, Bures, P., Leobandung, W., Ichikawa, H., Hydrogels in pharmaceutical formulations, Eur. J. Pharm. Biopharm., 50 (2000) 27-46.

[3] E.L. Lawrence, I.G. Turner, Materials for urinary catheters: a review of their histrory and development in the UK., Med. Eng. Phys., 27 (2005) 443-453.

[4] M.J. Lydon, T.W. Minett, B.J. Tighe, Cellular interactions with synthetic-polymer surfaces in culture, Biomaterials, 6 (1985) 396 - 402.

[5] H. Kumon, N. Hashimoto, M. Nishimura, K. Monden, N. Ono, Catheter-associated urinry tract infections: Impact of catheter materials on their management., Int. J. Antimicrob. Agents, 17 (2001) 311-316.

[6] S.F. John, V.F. Villier, M.R. Derrek, Adhesion of Staphylococci to polyurethane and hydrogel-coated polyurethane by an improved radiolabelling technique., J. Med. Microbiol., 43 (1995) 133-140.

[7] S.E. Tebbs, A. Sawyer, T.S. Elliot, Influence of surface morphology on in vitro bacterial adherence to central venous catheters., Brit. J. Anaesthol., 72 (1994) 587-591.

[8] T.M. Hamill, B.F. Gilmore, D.S. Jones, S.P. Gorman, Strategies for the development of the urinary catheter, Exp. Rev. Med. Dev., 4 (2007) 215-225.

[9] J. Jagur-Grodzinski, Polymeric gels and hydrogels for biomedical and pharmaceutical applications, Adv. Poly. Tech., 21 (2010) 27-47.

[10] K.H. Bouhadir, E. Alsberg, D.J. Mooney, Hydrogels for combination delivery of antineoplastic agents, Biomaterials, 22 (2001) 2625-2633.

[11] A. Kikuchi, T. Okano, Pulsatile Drug Release Control Using Hydrogels, Adv. Drug Deliv. Rev., 54 (2002) 53 - 77.

[12] T. Caykara, I. Aycicek, pH-responsive ionic poly(N,N-diethylaminoethylmethacrylate-co$\mathrm{N}$-vinyl-2-pyrrolidone) hydrogels: Synthesis and swelling properties., J. Polym. Sci. Part BPoly. Phys, 43 (2005) 2819-2828.

[13] A.R. Khare, N.A. Peppas, Release behaviour of bioactive agents from pH-sensitive hydrogels, J. Biomater. Sci. Polymer Ed., 4 (1993) 275 - 289.

[14] T. Inoue, G. Chen, K. Nakamae, A.S. Hoffman, A hydrophobically-modified bioadhesive polyelectrolyte hydrogel for drug delivery., J. Cont. Rel., 49 (1997) 167-176. 
[15] S.Y. Kim, Y.M. Lee, Drug release behaviour of eleectrical responsive poly(vinyl alcohol)/poly(acrylic acid) IPN hydrogels under an electric stimulus, J. Appl. Poly. Sci., 74 (1999) 1752-1761.

[16] S. Miyazaki, C. Yokouchi, M. Takada, External control of drug release: controlled release of insulin from a hydrophilic polymer implant by ultrasound irradiation in diabetic rats, J. Pharm. Pharmacol., 40 (1988) 716 - 717.

[17] C.P. McCoy, C. Rooney, C.R. Edwards, D.S. Jones, S.P. Gorman, Light-triggered moleculescale drug dosing devices, J. Amer. Chem. Soc., 129 (2007) 9572-9573.

[18] M.A. Cooperstein, H.E. Canavan, Biological cell detachment from poly(N-isopropyl acrylamide) and its applications., Langmuir, 26 (2010) 7695-7707.

[19] D.S. Jones, C.J. Lorimer, C.P. McCoy, S.P. Gorman, Characterisation of the physicochemical, antimicorbial and drug release properties of thermoresponsive hydrogel copolymers designed for medical device applications., J. Biomed. Mater. Res. Part B. Appl. Biomater., 85B (2008) 417-426.

[20] M. Kurisawa, M. Yokoyama, T. Okano, Gene expression control by temperature thermoresponsive polymeric gene carriers., J. Cont. Rel., 69 (2000) 127-137.

[21] D.C. Coughlan, F.P. Quilty, O.I. Corrigan, Effect of drug physicochemical properties on swelling/deswelling kinetics and pulsatile drug release, J. Cont. Rel., 98 (2004) 97-114.

[22] V.S. Mastiholimath, P.M. Dandragi, S.S. Jain, A.P. Gadad, A.R. Kulkami, Time and pH dependent colon specific pulsatile delivery of theophylline for nocturnal asthma., Int. J. Pharm., 328 (2007).

[23] J. Kopecek, Hydrogels: From soft contact lenses and implants to self-assembled nanomaterials., J. Poly. Sci. Part A: Polym. Chem., 47 (2009) 5929-5946.

[24] E. Valles, D. Durrando, I. Katime, E. Mendizabal, J.E. Puig, Equilibrium swelling and mechanical properties of hydrogels of acrylamiden and itaconic acid or its esters., Poly. Bull., 44 (2000) 109-114.

[25] T. Friedrich, B. Tieke, F.J. Stadler, C. Bailly, T. Eckhert, W. Richtering, Thermoresponsive copolymer hydrogels on the basis of $\mathrm{N}$-Isopropylacrylamide and a non-ionic surfactant monomer: Swelling behaviour, transparency and rheological properties, Macromolecules, 43 (2010) 9964-9971.

[26] C.G. Adair, S.P. Gorman, B.M. Feron, L.M. Byers, D.S. Jones, C.E. Goldsmith, J.E. Moore, J.R. Kerr, M.D. Curran, G. Hogg, C.H. Webb, G.J. McCarthy, K.R. Milligan, Implications of endotracheal tube biofilm for ventilator- associated pneumonia, Intens. Care Med., 25 (1999) 1072-1076. 
[27] C. Brady, S. Bell, C. Parsons, S. Gorman, D. Jones, C.P. McCoy, Novel porphyrinincorporated hydrogels for photoactive intraocular lens biomaterials, J. Phys. Chem. B, 111 (2007) 527-534.

[28] C. Parsons, C. McCcoy, S. Gorman, D. Jones, S. Bell, C. Brady, S. McGlinchey, Antiinfective photodynamic biomaterials for the prevention of intraocular lens-associated infectious endophthalmitis, Biomaterials, 30 (2009) 597-602.

[29] D.S. Jones, D.W.J. McLaughlin, C.P. McCoy, S.P. Gorman, Physicochemical characterisation and biological evaluation of hydrogel-poly(e-caprolactone) interpenetrating polymer networks as novel urinary biomaterials., Biomaterials, 26 (2005) 1761-1770.

[30] D.S. Jones, Pharmaceutical Statistics, The Pharmaceutical Press, London, 2002.

[31] N.A. Peppas, Analysis of Fickian and non-Fickian drug release from polymers, Acta Pharm. Helv., 60 (1985) 110-111.

[32] J. Kopecek, Hydrogels: From soft contact lenses and implants to self-assembled nanomaterials, J. Poly. Sci: Part A: Poly Chem., 47 (2009) 5829-5946.

[33] L. Geever, C. Higginbotham, Temperature-triggered gelation and controlled drug release via NIPAAm/NVP-based hydrogels J. Mater. Sci., 46 (2011) 3233-3240.

[34] G. Fundueanu, M. Constantin, C. Stanciu, G. Theodoridis, P. Ascenzi, pH and temperature-sensitive polymeric microspheres for drug delivery: the dissolution of copolymers modulates drug release, J. Mater. Sci.-Mater. Med., 20 (2009) 2465-2475.

[35] D.S. Jones, A.F. Brown, A.D. Woolfson, Solute and solvent effects on the thermorheological properties of poly(oxyethylene)-poly(oxypropylene) block copolymers: Implications for pharmaceutical dosage form design, Journal of Applied Polymer Science, 87 (2003) 1016-1026.

[36] E. Baloglu, S. Karavana, Z. Senyigit, S. Hilmioglu-Polat, D. Metin, O. Zekioglu, Guneri, T., D. Jones, In-situ gel formulations of econazole nitrate:preparation and in-vitro and in-vivo evaluation., J. Pharm. Pharmacol., 63 (2011) 1274-1282.

[37] D.S. Jones, C.P. Lorimer, G.P. Andrews, C.P. McCoy, S.P. Gorman, An examination of the thermorheological and drug release properties of zinc tetraphenylporphyrin-containing thermoresponsive hydrogels, designed as light activated antimicrobial implants, Chem. Eng. Sci., 62 (2007) 990-999.

[38] D.S. Jones, C.P. Lorimer, C.P. McCoy, S.P. Gorman, Characterisation of the physicochemical, antimicrobial and drug release properties of thermoresponsive hydrigel copolymers designed for medical device applications., J. Biomed. Mater. Res. Part B. Appl. Biomater., 85 (2008) 417-426. 
[39] C. Kavanagh, Y. Rochev, W. Gallagher, K. Dawson, A. Keenan, Local drug delivery in restenosis injury: thermoresponsive co-polymers as potential drug delivery systems, Pharmacol. Ther., 102 (2004) 1-5.

[40] Y.H. Bae, Okano., R. Hsu, S. Kim, Thermoresponsive polymers as on-off switches for drug release., Makromol. Chemie-Rapid Comm., 8 (1987) 481-485.

[41] K.B. Doorty, T.A. Golubeva, A.V. Gorelov, Rochev. Y.A., L.T. Alle, Dawson., K.A., W.M. Gallagher, Keenan, A.K., Poly(N-isopropylacrylamide) co-polymer films as potential vehicles for delivery of an antimitotic agent to vascular smooth muscle cells., Cardiovasc. Pathol., 12 (2003) 105-110.

[42] M. Ham, Y. Kim, Property modulation of Poly( $\mathrm{N}$-isopropylacrylamide) hydrogels by incorporation of modified silica, Poly. Eng. Sci., 48 (2008) 2439-2445.

[43] L. Geever, M. Nugent, C. Higginbotham, The effect of salts and pH buffer solutions on the phase transition temperature and swelling of thermoresponsive pseudogels based on $\mathrm{N}$ isopropylacrylamide., J. Mater. Sci., 42 (2007) 9845-9854.

[44] L. Geever, D. Devine, M. Nugent, C. Higginbotham, J. Kennedy, J. Lyons, A. Hanley, Lower critical temperature control and swelling behaviour of physically crosslinked thermosensitive copolymers based on N-isopropylamide., Eur. Polym. J., 42 (2006) 25402548.

[45] C.G. Pitt, Polycaprolactone and Its Copolymers, in: M. Chasin, R. Langer (Eds.) Biodegradable Polymers as Drug Delivery Systems, Marcel Dekker, New York, 1990, pp. 71 120.

[46] P. Douglas, G. Andrews, D.S. Jones, G. Walker, Analysis of in vitro dissolution from PCL melt extrusion, Chem. Eng. J., 164 (2010) 359-370.

[47] S. Rakmee, Y. Ruksalkulpiwat, W. Sutapun, N. Suppakarn, Effects of mixing technique and filler content on physical properties of bovine bone-based CHA/PLA composites, J. Appl. Polym. Sci., 122 (2011) 2433-2441.

[48] D.S. Jones, J.G. McGovern, A.D. Woolfson, C.G. Adair, S.P. Gorman, Physicochemical characterization of hexetidine-impregnated endotracheal tube poly(vinyl chloride) and resistance to adherence of respiratory bacterial pathogens, Pharm. Res., 19 (2002) 818-824.

[49] N.A. Peppas, Analysis of Fickian and Non-Fickian Drug Release from Polymers, Pharm. Acta Helvet., 60 (1985) 110-111.

[50] S.P. Gorman, J.G. McGovern, A.D. Woolfson, C.G. Adair, D.S. Jones, The concomitant development of poly(vinyl chloride)-related biofilm and antimicrobial resistance in relation to ventilator- associated pneumonia, Biomaterials, 22 (2001) 2741-2747. 
[51] D. Balazs, K. Triandafillu, P. Wood, Y. Chevolot, C. van Delden, H. Harms, C. Hollenstein, H. Mathieu, Inhibition of bacterial adhesion on PVC endotracheal tubes by RF-oxygen glow discharge, sodium hydroxide and silver nitrate treatments., Biomaterials, 25 (2004) 21392151.

[52] L. Berra, T. Kolobow, P. Laquerriere, B. Pitts, S. Bramati, J. Pohlmann, C. Marelli, M. Panzeri, P. Brambillasca, F. Villa, A. Baccarelli, S. Bouthors, H. Stelfox, L. Bigatello, J. Moss, A. Pesenti, Internally coated endotracheal tubes with silver sulfadiazine in polyurethane to prevent bacterial colonisation: a clinical trial, Inten. Care Med., 34 (2008) 1030-1037.

[53] C.G. Adair, S.P. Gorman, L.M. Byers, D.S. Jones, B. Feron, M. Crowe, H.C. Webb, G.J. McCarthy, K.R. Milligan, Eradication of endotracheal tube biofilm by nebulised gentamicin, Intens. Care Med., 28 (2002) 426-431. 
Table One. The effect of polymer composition on the mechanical properties of hydrogels and hydrogel-PCL semi-interpenetrating polymer networks

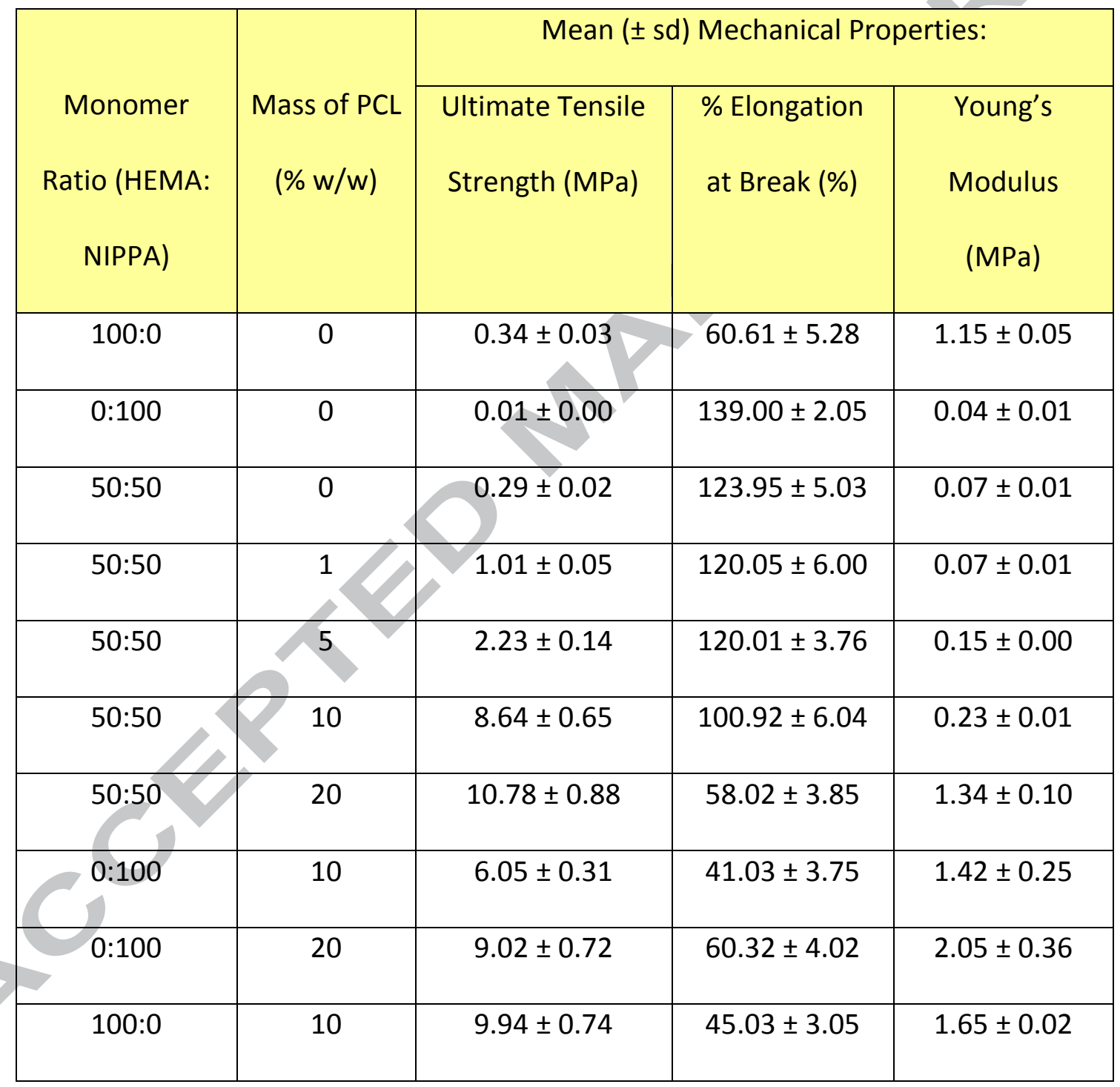


Table Two. The effect of polymer composition and temperature on the equilibrium swelling ratio of hydrogels and hydrogel-PCL semiinterpenetrating polymer networks at $\mathrm{pH} 7$

\begin{tabular}{|c|c|c|c|}
\hline \multirow[t]{2}{*}{$\begin{array}{c}\text { Ratio of HEMA: } \\
\text { NIPAA }\end{array}$} & \multirow[t]{2}{*}{$\begin{array}{l}\text { Concentration of } \mathrm{PCL} \\
\qquad(\% \mathrm{w} / \mathrm{w})\end{array}$} & \multicolumn{2}{|c|}{$\begin{array}{l}\text { Mean ( } \pm \mathrm{sd} \text { ) Equilibrium Swelling Ratio of } \\
\text { Networks in pH } 7 \text { buffer at: }\end{array}$} \\
\hline & & $20^{\circ} \mathrm{C}$ & $37^{\circ} \mathrm{C}$ \\
\hline $100: 0$ & 0 & $0.62 \pm 0.03$ & $0.63 \pm 0.05$ \\
\hline $0: 100$ & 0 & $7.39 \pm 0.36$ & $0.40 \pm 0.03$ \\
\hline $50: 50$ & 1 & $1.13 \pm 0.09$ & $0.44 \pm 0.05$ \\
\hline $50: 50$ & 5 & $1.01 \pm 0.03$ & $0.39 \pm 0.02$ \\
\hline $50: 50$ & 10 & $0.99 \pm 0.04$ & $0.35 \pm 0.01$ \\
\hline $50: 50$ & 20 & $0.80 \pm 0.03$ & $0.32 \pm 0.01$ \\
\hline $100: 0$ & & $0.50 \pm 0.03$ & $0.48 \pm 0.02$ \\
\hline $0: 100$ & 10 & $6.93 \pm 0.45$ & $0.52 \pm 0.02$ \\
\hline $0: 100$ & 20 & $5.58 \pm 0.28$ & $0.40 \pm 0.02$ \\
\hline
\end{tabular}


Table Three. The effect of polymer composition and temperature of the dissolution medium ( $\mathrm{pH} 7.4)$ on the time required to release a defined $\%$ of the original drug loading from hydrogels and hydrogel-PCL semiinterpenetrating polymer networks

\begin{tabular}{|c|c|c|c|c|c|}
\hline \multirow[b]{2}{*}{$\begin{array}{l}\text { Conc. of } \\
\text { PCL (\%) }\end{array}$} & \multirow[b]{2}{*}{$\begin{array}{l}\text { Ratio of } \\
\text { HEMA: NIPAA }\end{array}$} & \multirow[b]{2}{*}{$\begin{array}{l}\text { Temp } \\
\left({ }^{\circ} \mathrm{C}\right)\end{array}$} & \multicolumn{3}{|c|}{$\begin{array}{l}\text { Time required to release a defined } \% \text { of the } \\
\text { original mass of loaded drug ( } \mathrm{min} \text { ) }\end{array}$} \\
\hline & & & Time 10\% & Time $30 \%$ & Time 50\% \\
\hline 1 & $50: 50$ & 20 & $20.99 \pm 1.22$ & $66.2 \pm 3.11$ & $163.88 \pm 10.21$ \\
\hline 5 & $50: 50$ & 20 & $22.53 \pm 1.80$ & $75.94 \pm 5.13$ & $193.16 \pm 15.51$ \\
\hline 10 & $50: 50$ & 20 & $25.18 \pm 1.79$ & $92.57 \pm 6.24$ & $241.82 \pm 16.24$ \\
\hline 20 & $50: 50$ & 20 & $27.27 \pm 2.01$ & $105.7 \pm 7.56$ & $283.59 \pm 15.45$ \\
\hline 1 & $50: 50$ & 37 & $21.38 \pm 1.62$ & $68.71 \pm 3.84$ & $168.65 \pm 13.41$ \\
\hline 5 & $50: 50$ & 37 & $23.15 \pm 1.40$ & $79.81 \pm 4.51$ & $204.43 \pm 14.74$ \\
\hline 10 & $50: 50$ & 37 & $25.51 \pm 1.49$ & $94.66 \pm 8.65$ & $248.48 \pm 12.41$ \\
\hline 20 & $50: 50$ & 37 & $27.79 \pm 2.14$ & $109.02 \pm 15.43$ & $294.15 \pm 16.45$ \\
\hline 10 & $0: 100$ & 20 & $25.79 \pm 1.74$ & $96.41 \pm 7.45$ & $254.38 \pm 12.45$ \\
\hline 10 & $0: 100$ & 37 & $6.49 \pm 0.34$ & $19.46 \pm 1.24$ & $34.43 \pm 2.41$ \\
\hline 20 & $100: 0$ & 20 & $25.47 \pm 1.20$ & $98.27 \pm 6.41$ & $247.79 \pm 13.47$ \\
\hline 20 & $100: 0$ & 37 & $26.40 \pm 1.69$ & $104.83 \pm 7.12$ & $262.43 \pm 13.49$ \\
\hline 20 & $0: 100$ & 20 & $8.95 \pm 0.45$ & $120.01 \pm 7.42$ & $279.02 \pm 10.04$ \\
\hline 20 & $0: 100$ & 37 & $7.92 \pm 0.38$ & $22.02 \pm 1.00$ & $40.04 \pm 2.04$ \\
\hline
\end{tabular}


Table Four. The effect of polymer composition and temperature on release exponent of metronidazole from semi-interpenetrating polymer networks

\begin{tabular}{|c|c|c|c|}
\hline \multicolumn{2}{|c|}{ Network Composition } & \multicolumn{2}{|c|}{ Mean $( \pm \mathrm{sd})$ release exponent at $\left({ }^{\circ} \mathrm{C}\right)$} \\
\hline PCL Conc ${ }^{n}(\% w / w)$ & $\begin{array}{c}\text { Ratio of HEMA: } \\
\text { NIPAA }\end{array}$ & $20^{\circ} \mathrm{C}$ & $37^{\circ} \mathrm{C}$ \\
\hline 0 & $100: 0$ & $0.64 \pm 0.02$ & $0.66 \pm 0.04$ \\
\hline 0 & $0: 100$ & $0.65 \pm 0.03$ & - \\
\hline 1 & $50: 50$ & $0.47 \pm 0.03$ & $0.48 \pm 0.02$ \\
\hline 5 & $50: 50$ & $0.47 \pm 0.03$ & $0.47 \pm 0.03$ \\
\hline 10 & $50: 50$ & $0.46 \pm 0.03$ & $0.47 \pm 0.03$ \\
\hline 20 & 50:50 & $0.48 \pm 0.03$ & $0.48 \pm 0.03$ \\
\hline 10 & 100:0 & $0.47 \pm 0.03$ & $0.48 \pm 0.03$ \\
\hline 10 & $0: 100$ & $0.49 \pm 0.03$ & - \\
\hline 20 & $0: 100$ & $0.50 \pm 0.02$ & - \\
\hline
\end{tabular}

Release exponent could not be measured due to thermoresponsive release 
Table Five. The thermal properties of sequential interpenetrating polymer networks

\begin{tabular}{|c|c|c|c|c|}
\hline $\begin{array}{l}\text { Ratio of NIPAA: } \\
\text { HEMA }\end{array}$ & $\begin{array}{l}\text { Concentration of } \\
\text { PCL }(\% w / w)\end{array}$ & Endotherm $1\left({ }^{\circ} \mathrm{C}\right)^{\mathrm{a}}$ & $\begin{array}{l}\text { Endotherm } 2 \\
\left({ }^{\circ} \mathrm{C}\right)^{\mathrm{b}}\end{array}$ & $\begin{array}{l}\text { Endotherm } 3 \\
\left({ }^{\circ} \mathrm{C}\right)^{b}\end{array}$ \\
\hline $100: 0$ & 0 & $31.51 \pm 1.52$ & $142.04 \pm 2.02$ & ND \\
\hline 100:0 & 20 & $31.49 \pm 1.23$ & $141.95 \pm 2.06$ & $58.05 \pm 2.01$ \\
\hline $50: 50$ & 0 & $34.87 \pm 1.02$ & $130.05 \pm 1.83$ & ND \\
\hline $50: 50$ & 20 & $35.23 \pm 0.85$ & $131.83 \pm 1.63$ & $58.95 \pm 2.84$ \\
\hline
\end{tabular}

ND Not Determined

a Sol-gel transition temperature

b Glass transition temperature

c Melting endotherm of $\mathrm{PCL}$ 
Figure 1. The release of metronidazole from semi-interpenetrating polymer networks composed of PCL ( $10 \% \mathrm{w} / \mathrm{w})$ and $\mathrm{p}$ (NIPAA, circles), p(NIPAA-co-HEMA, triangles) or $\mathrm{p}\left(\mathrm{HEMA}\right.$, squares) at $20^{\circ} \mathrm{C}$ (closed symbols) and $37^{\circ} \mathrm{C}$ (open symbols)

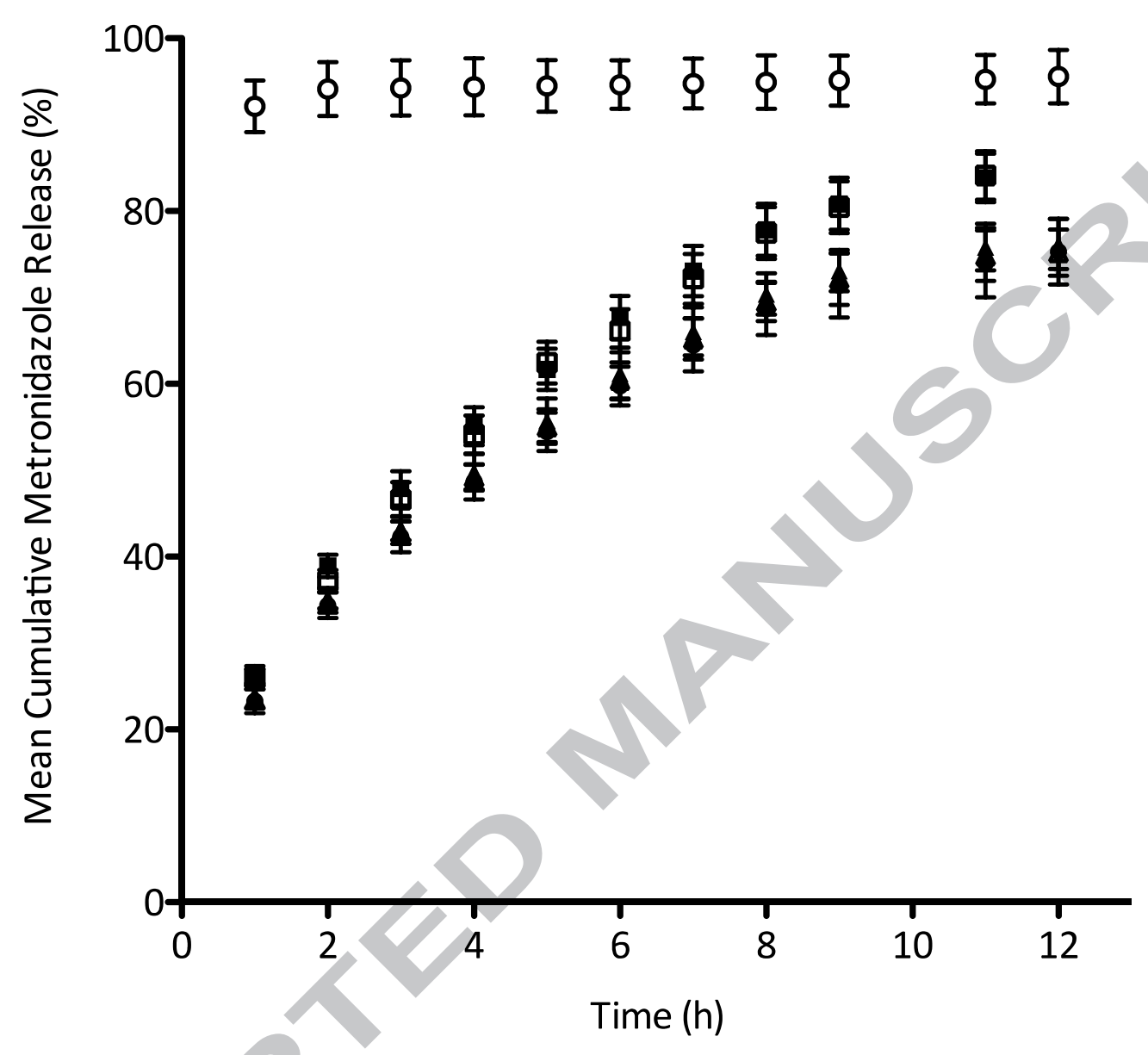


Figure 2. Confocal laser scanning micrographs showing a model semiinterpenetrating polymer network based on p(HEMA-co-NIPAA) and 10\% w/w PCL: (a) stained with acridine orange, (b) stained with rhodamine $B,(c)$ simultaneously stained with both acridine orange and rhodamine $B$

\section{Figure 2 (a)}

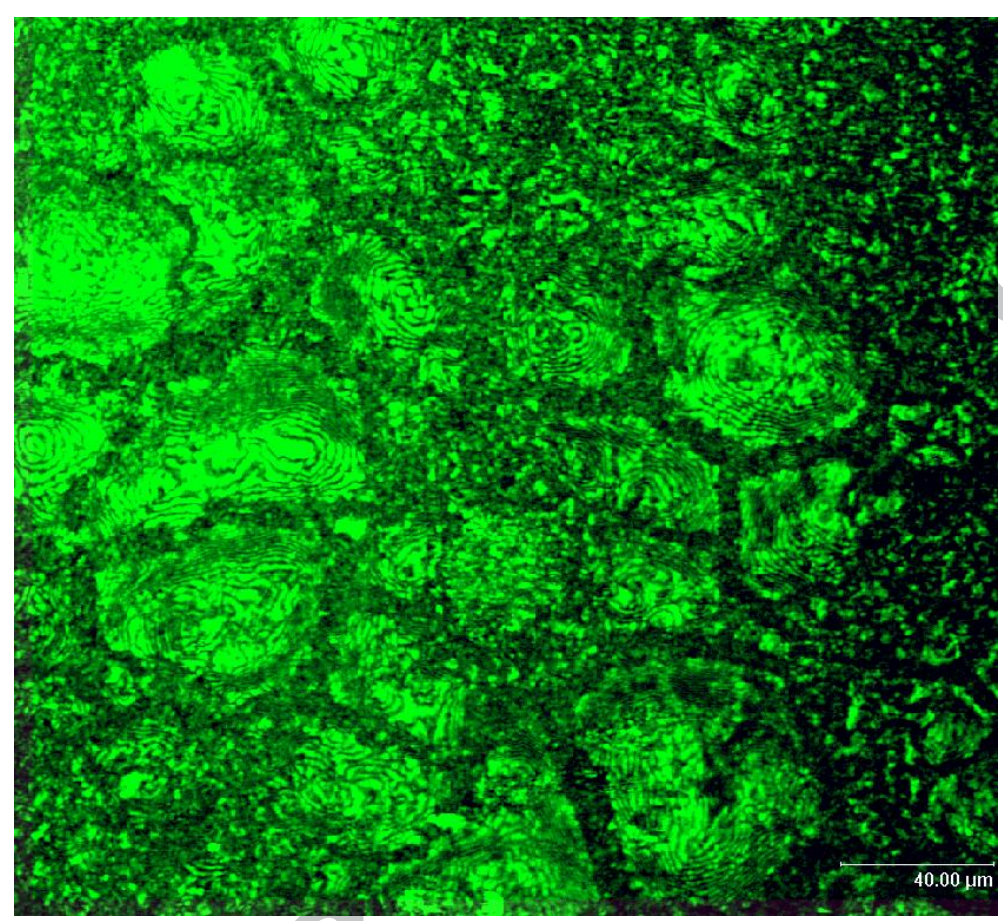


Figure 2 (b)

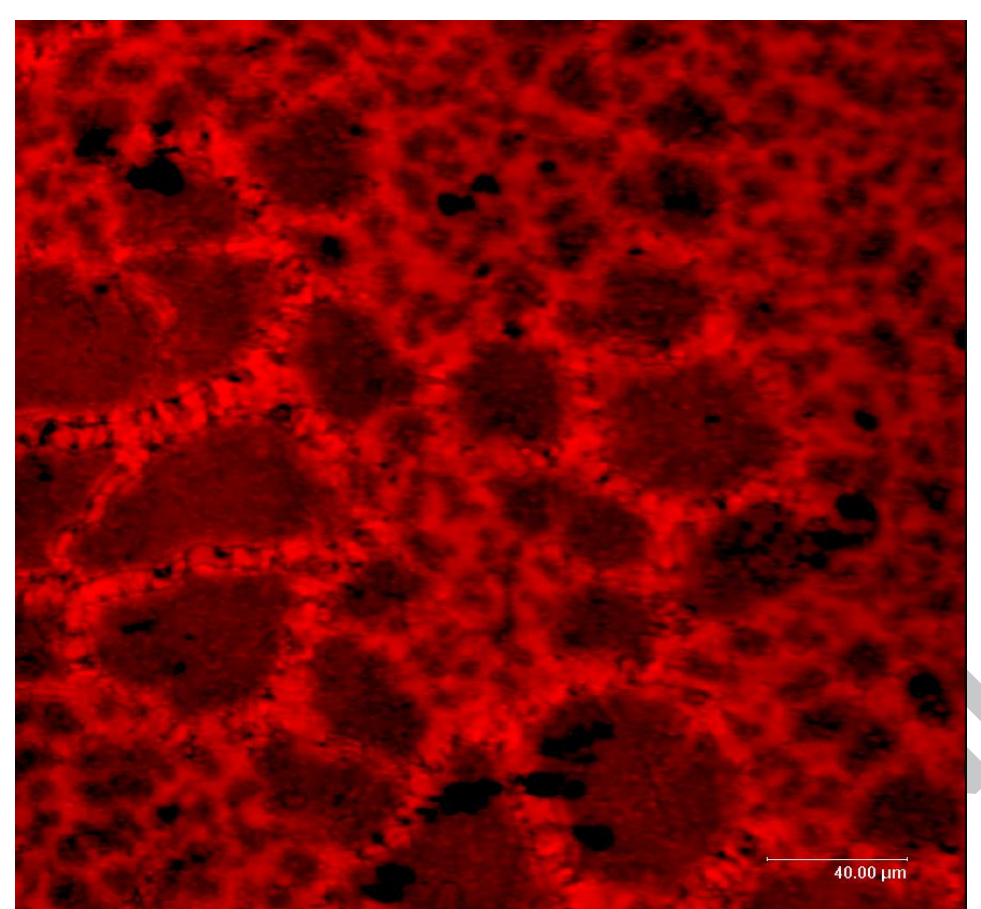

Figure 2 (c)

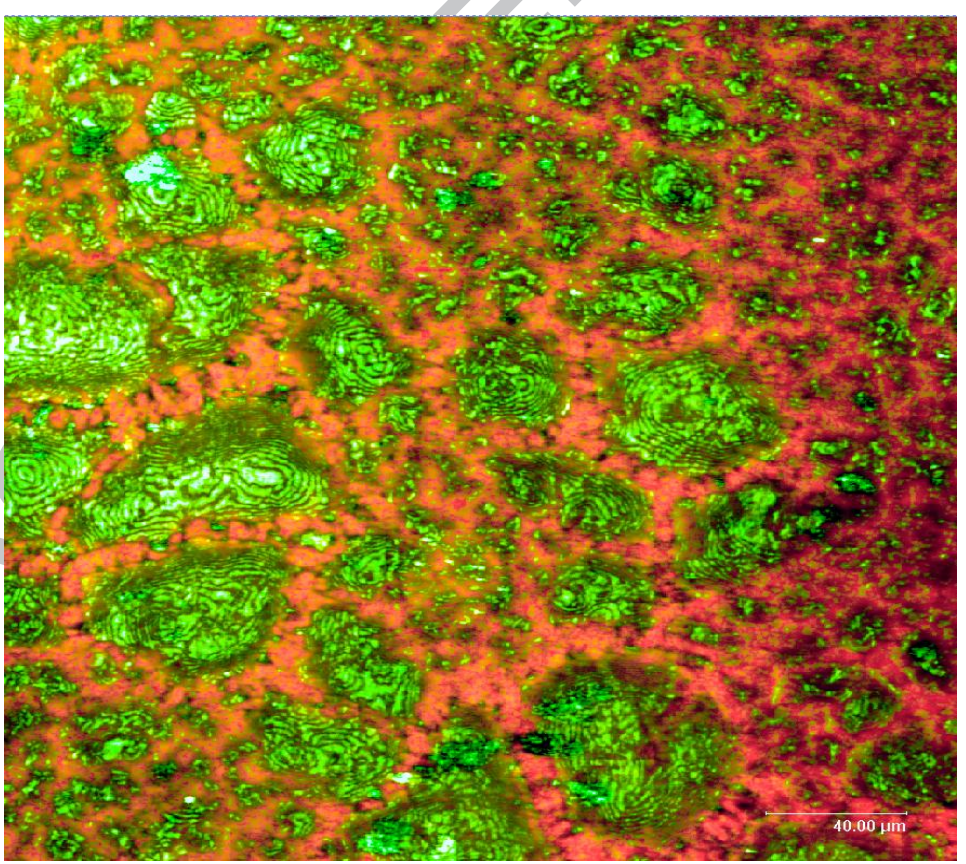




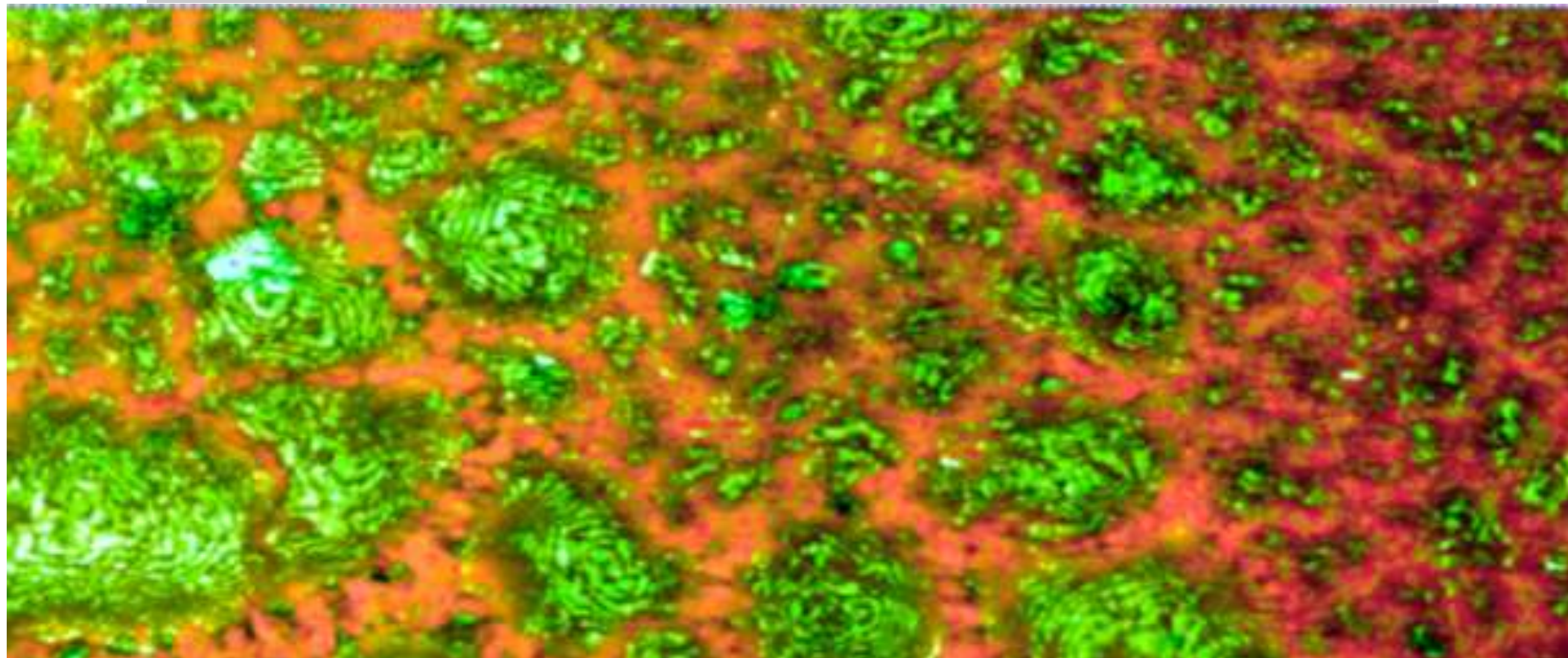

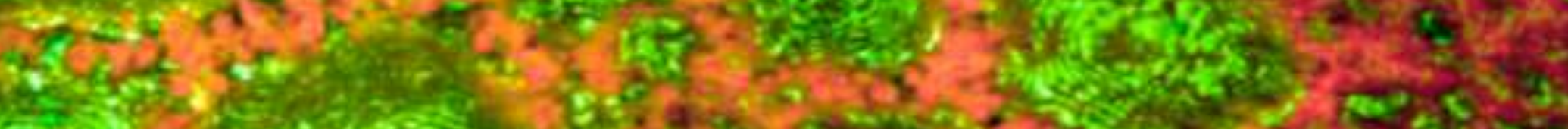

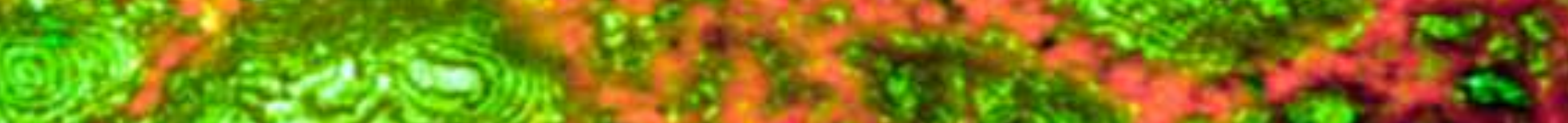

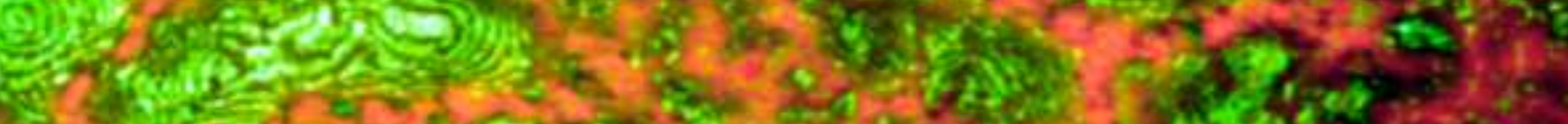

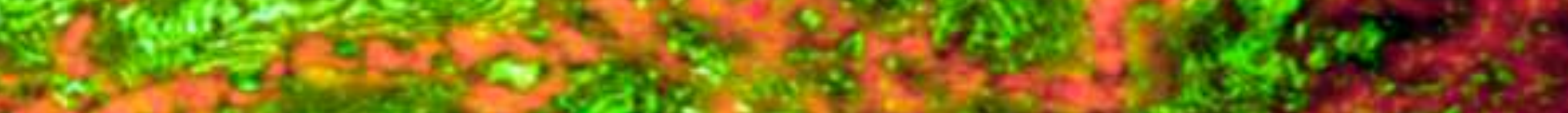

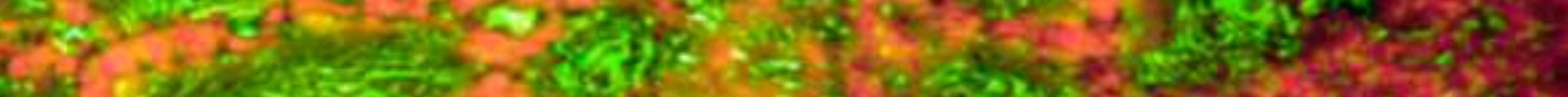
201.

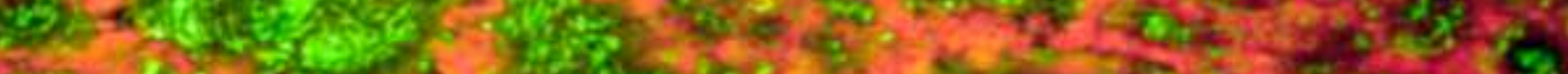

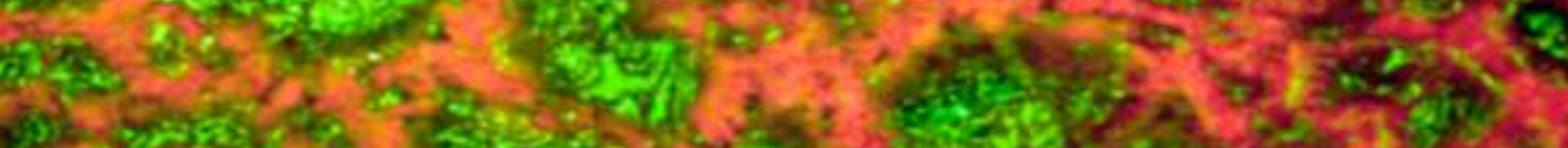

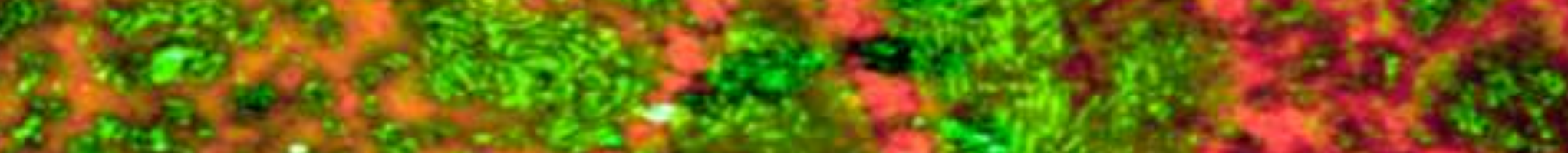

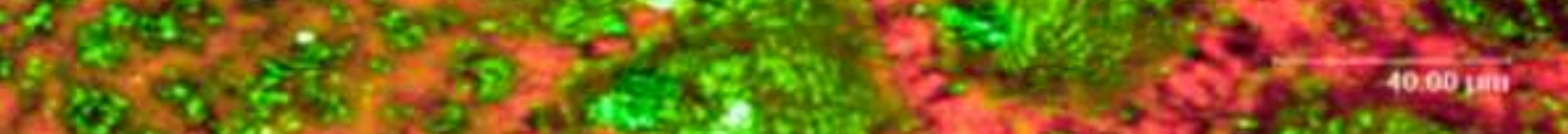
senes $\nabla$ 